Bull. Mater. Sci., Vol. 3, Number 2, July 1981 pp. 169-184. (C) Printed in India.

\title{
Oxide dielectrics
}

\author{
E C SUBBARAO \\ Department of Metallurgical Engineering, Indian Institute of Technology, \\ Kanpur 208 016, India \\ MS received 19 January 1981
}

\begin{abstract}
Three aspects of oxide dielectrics are covered (i) structure engineering: making use of crystal structure and crystal chemistry, the dielectric behaviour can be finely tuned, as illustrated in the systems $(\mathrm{Ba}, \mathrm{Pb})(\mathrm{Ti}, \mathrm{Zr}) \mathrm{O}_{3}$ and $(\mathrm{Ba}, \mathrm{Pb})(\mathrm{Ti}, \mathrm{Nb}) \mathrm{O}_{3}$ studied by Biswas. (ii) Defect structure: control of defect structure of Mn-doped $\mathrm{BaTiO}_{3}$ inhibits the reduction of $\mathrm{BaTiO}_{3}$ in reducing atmospheres at high temperatures thus making the use of base metal electrodes possible in manufacturing ceramic capacitors. (iii) Composites: Diphasic composites of oxide dielectrics with other materials may be utilized for producing voltage stable capacitors and dense or flexible piezoelectrics with outstanding properties.
\end{abstract}

Keywords. Dielectrics; ferroelectrics; defect structure; composites; piezoelectrics.

\section{Introduction}

Ferroelectrics are an important class of oxide dielectrics. Though the first ferroelectric (Rochelle salt) was discovered nearly sixty years ago, the first oxide ferroelectric $\left(\mathrm{BaTiO}_{3}\right)$ was found less than forty years ago. These materials possess high dielectric constants (which make them useful in capacitors), high piezoelectric constants (useful in electromechanical transducers) and high pyroelectric coefficients (valuable in thermal sensing). Expanding understanding of the physics and chemistry of the solid state has been applied to systematically develop better oxide dielectrics. Manipulation of structure at various levels-electronic, atomic, micro and macrohas been employed to enhance properties of these materials, sometimes by orders of magnitude. These aspects are examined here with appropriate illustrations.

\section{Structure engineering}

The most important common feature of oxide ferroelectrics is the existence of oxygen octahedra, which are linked to form a three-dimensional lattice. The octahedra are quite often puckered, lowering the symmetry of the crystal. The extent of puckering is dependent upon the ions located in the cavities formed by the oxygen octahedra. A small, highly charged ion such as $\mathrm{Ti}, \mathrm{Zr}, \mathrm{Nb}$ or $\mathrm{Ta}$ is located inside the octahedron in an off-centre position. Oxygen octahedra are linked to give rise to three structure- 
types which exhibit ferroelectric behaviour, each of which exhibits polymorphism e.g., perovskite-cubic, tetragonal, orthorhombic, rhombohedral, pyrochlore-cubic, rhombohedral; and tungsten bronze type-orthorhombic, tetragonal (see, for example, Jona and Shirane 1962). Ionic substitutions with size, charge and polarizability of the ions as parameters provide means to finely tune the structure and thereby the properties of these oxide ferroelectrics, which was carried out by Professor A B Biswas in establishing structure maps of the systems $(\mathrm{Ba}, \mathrm{Pb})_{1-\delta}(\mathrm{Ti}, \mathrm{Nb}) \mathrm{O}_{3}$ and $(\mathrm{Ba}, \mathrm{Pb})(\mathrm{Ti}, \mathrm{Zr}) \mathrm{O}_{3}$.

\section{$2.1(\mathrm{Ba}, \mathrm{Pb})_{1-\delta}(\mathrm{Ti}, \mathrm{Nb}) \mathrm{O}_{3}$ system}

This system is of significance, since it includes a number of ferroelectric compounds$\mathrm{BaTiO}_{3}, \mathrm{PbTiO}_{3}$ and $\mathrm{PbNb}_{2} \mathrm{O}_{6}$, and extensive ferroelectric solid solutions- $(\mathrm{Ba}, \mathrm{Pb})$ $\mathrm{TiO}_{3},(\mathrm{Ba}, \mathrm{Pb}) \mathrm{Nb}_{2} \mathrm{O}_{6}$, etc. For compositions sintered at $1280-1300^{\circ} \mathrm{C}$ in $\mathrm{PbO}$ atmosphere for $1 \mathrm{hr}$, Srikanta et al (1962) have cstablished the structure map for this system (figure 1 ). In this two-dimensional diagram, a point $x, y$ represents the composition $\mathrm{Ba}_{y} \mathrm{~Pb}_{1-y-x / 2} \mathrm{Ti}_{x} \mathrm{Nb}_{1-x} \mathrm{O}_{3}$.

(A) Cubic perovskite arises when the incorporation of $\mathrm{Nb}$ for $\mathrm{Ti}$ in $(\mathrm{Ba}, \mathrm{Pb}) \mathrm{TiO}_{3}$ creates vacancies in the $\mathrm{A}$ sites of the $\mathrm{ABO}_{3}$ lattice and raises the symmetry to cubic. Density and $\mathrm{X}$-ray intensity data confirm the formula as $\mathrm{A}_{1-\delta} \mathrm{BO}_{3}$, similar to that of $\mathrm{Ba}(\mathrm{Ti}, \mathrm{Nb}) \mathrm{O}_{3}$ system (Subbarao and Shirane 1959).

(B) Tetragonal perovskite is stable for compositions with $\mathrm{Nb}^{5+}<0 \cdot 1$, and for compositions with $\mathrm{Nb}^{5+}>0 \cdot 1$ only if the $\mathrm{Pb}^{2+}$ content is high. The tetragonal distortion decreases as $\mathrm{Pb}^{2+}$ is replaced by $\mathrm{Ba}^{2+}$ or $\mathrm{Ti}^{4+}$ by $\mathrm{Nb}^{5+}$ along line $x y$ in figure 1 .

(C) Orthorhombic perovskite region is only approximately fixed in figure 1.

(D) Cubic pyrochore. These compositions have the general formula $(\mathrm{Pb}, \mathrm{Ba})_{1-\delta}$ $(\mathrm{Nb} \mathrm{Ti}) \mathrm{O}_{3}$ with $\delta=0.15$ to $0.375, \mathrm{Ba}^{2+}=0$ to 0.225 and $\mathrm{Nb}^{5+}=0.3$ to 0.75 . Density

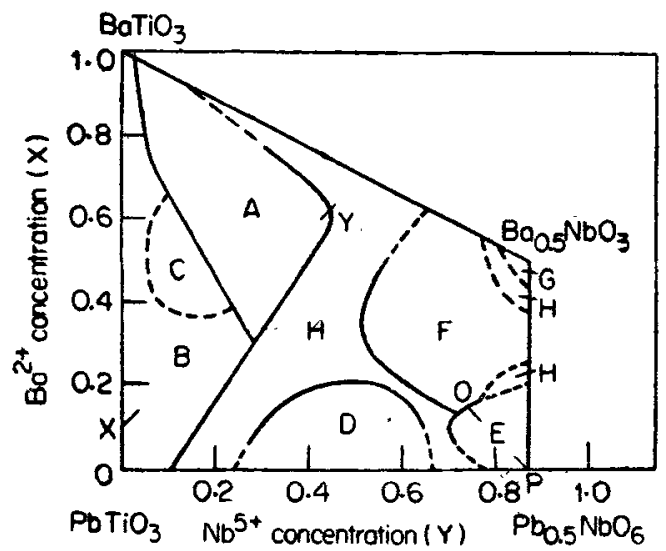

Figure 1. Structure map of $(\mathrm{Ba}, \mathrm{Pb})_{1-\delta}(\mathrm{Ti}, \mathrm{Nb}) \mathrm{O}_{3}$ system (after Srikanta et al 1962).

(A) Cubic perovskite phase; (B) Tetragonal $\mathrm{BaTiO}_{3}$ type; (C) Orthorhombic $\mathrm{BaTiO}_{3}$ type; (D) Cubic pyrochore type; (E) Orthorhombic $\mathrm{PbNb}_{2} \mathrm{O}_{6}$ type; (F) Tetragonal $\mathrm{PbNb}_{2} \mathrm{O}_{6}$ type; (G) Orthorhombic $\mathrm{BaNb}_{2} \mathrm{O}_{6}$ type; (H) Mixture phase. 
data suggest vacancies in the $16(d)$ (occupancy 11.3 to 12.6 out of 16 ) and oxygen (occupancy $47 \cdot 1$ to $50 \cdot 1$ out of 56) sites. Thus it may be similar to $\mathrm{Pb}_{1.5} \mathrm{Nb}_{2} \mathrm{O}_{6.5}$ (Cook and Jaffe 1953). The electrical conductivity is quite low and hence mixed valency is not likely for any of the ions.

(E) Orthorhombic tungsten bronze $\left(\mathrm{PbNb}_{2} \mathrm{O}_{6}\right)$ type. This occurs in the vicinity of $\mathrm{PbNb}_{2} \mathrm{O}_{6}(a=17.65, b=17.91, c=7.736 \AA$ and $z=20)$. The orthorhombic distortion $b / a$ is maximum $(1.014)$ for pure $\mathrm{PbNb}_{2} \mathrm{O}_{6}$ and decreases along the line $\mathrm{PO}$ in figure 1 as $\mathrm{Nb}^{5+}$ and $\mathrm{Pb}^{2+}$ are replaced by $\mathrm{Ti}^{4+}$ and $\mathrm{Ba}^{2+}$ respectively. The crystal structure of the orthorhombic phase is shown in figure 2, which shows the tunnel and cage sites which are surrounded by five and four oxygen octahedra respectively (Francombe and Lewis 1958). There are 16 tunnel and 8 cage sites in a unit cell, out of which 20 are filled by $\mathrm{Pb}^{2+}$ ions in the case of $\mathrm{PbNb}_{2} \mathrm{O}_{6}$. The larger coordination number of tunnel sites and lower repulsive energy of ions in these sites must favour the filling of tunnel sites first. It is likely that 4 cage (smaller) sites are vacant. The measured densities suggest that the maximum number of $A$ ions that can be accommodated at the $\mathrm{A}$ sites depends on the $\mathrm{Pb}: \mathrm{Ba}$ ratio. As shown in figure 3, the maximum occupancy is 22 for pure lead compounds (point $A$ ) and increases with increasing $\mathrm{Ba}$ content (A to $\mathrm{B}$ ) up to the maximum permissible value of 24 . At still higher $\mathrm{Ba}: \mathrm{Pb}$ ratio, the maximum value of $\mathrm{A}$ site occupancy decreases from 24 to 20 along $B C$, possibly because the large $A$ ions tend to change the orthorhombic structure to a tetragonal one.

(F) Tetragonal tungsten bronze type. The measured density values indicate $5 \cdot 1$ to $6.2,8.9$ to 9.7 and 26.7 to 29.1 ions at the A, B and O sites respectively, on the assumption that the ratio of metal-to-oxygen has remained unchanged during sintering.

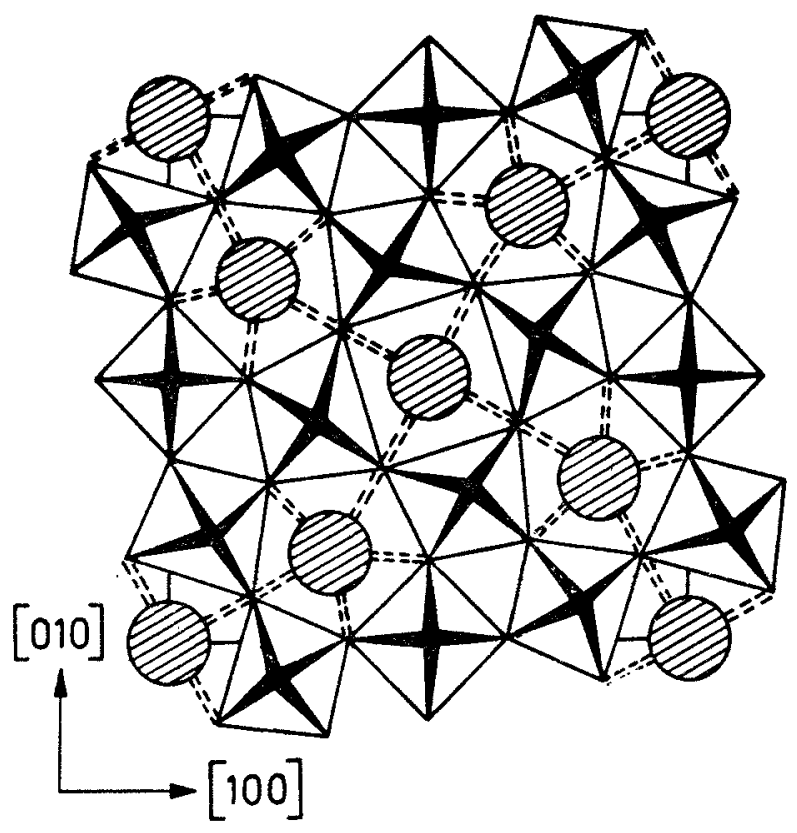

Figure 2. Projection of the structure of tetragonal tungsten bronze $\left(\mathrm{K}_{\mathbf{0}_{57}} \mathrm{WO}_{\mathbf{3}}\right)$ or paraelectric $\mathrm{Pb}, \mathrm{Nb}_{2} \mathrm{O}_{6}$ parallel to [001]. $\mathrm{K}^{+}$or $\mathrm{Pb}^{2+}$ ions (circles) are located $(Z=0)$ in 'tunnels'- or 'cages' formed by $\mathrm{WO}_{6}$ or $\mathrm{NbO}_{6}$ octahedra $\left(Z= \pm \frac{1}{2}\right)$. 


$$
\begin{gathered}
\text { Total number of ions per } \\
\text { unit cell at } A \text { sites }
\end{gathered}
$$

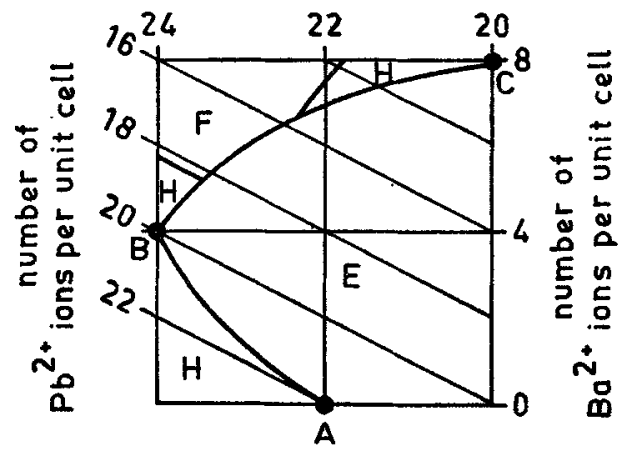

Figure 3. Occupancy of tunnel and cage sites in orthorhombic tungsten bronze structure with varying $\mathrm{Ba} / \mathrm{Pb}$ ratio (after Srikanta et al 1962).

(E) $\mathrm{PbNb}_{2} \mathrm{O}_{6}$ Orthorhombic; (F) $\mathrm{PbNb}_{2} \mathrm{O}_{6}$ tetragonal; (H) Mixture.

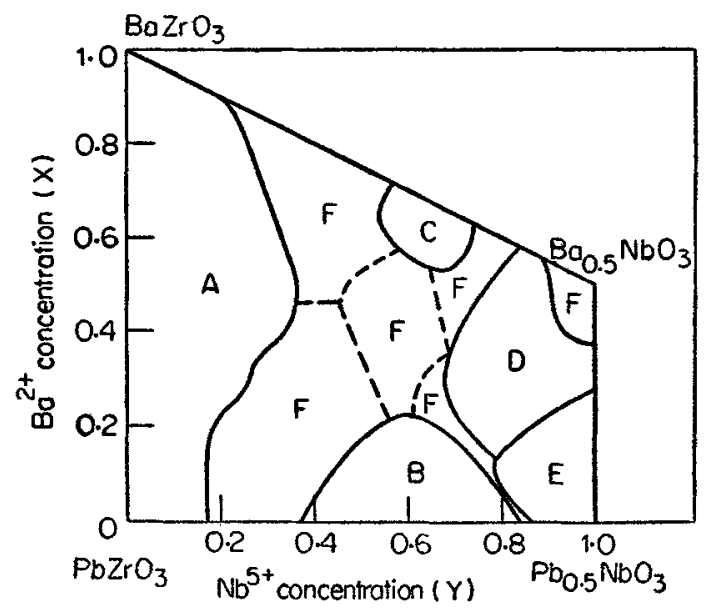

Figure 4. Structure map of $(\mathrm{Ba}, \mathrm{Pb})(\mathrm{Nb}, \mathrm{Zr}) \mathrm{O}_{3}$ system (after Chincholkar et al 1969).

(A) Cubic perovskite phase; (B) Cubic pyrochlore type; (C) Tetragonal $\mathrm{PbTiO}_{3}$ type; (D) Tetragonal tungsten bronze type; (E) Orthorhombic $\mathrm{PbNb}_{2} \mathrm{O}_{6}$ type; (F) Mixture phase.

(G) Barium niobate phase is stable in a narrow region near the orthorhombic $\mathrm{BaNb}_{2} \mathrm{O}_{6}$ phase $(a=12 \cdot 17, b=10.25$ and $c=3.94 \AA$ ) (Francombe 1960).

(H) Two-phase regions separate the four structure types (perovskite, tungsten bronze, pyrochlore, $\mathrm{BaNb}_{2} \mathrm{O}_{6}$ ) from each other.

\section{$2.2(\mathrm{Ba}, \mathrm{Pb})(\mathrm{Nb}, \mathrm{Zr}) \mathrm{O}_{3}$ system}

A two-dimensional constitution diagram for this system is shown in figure 4, where a point $(x, y)$ represents the composition $\mathrm{Ba}_{x} \mathrm{~Pb}_{1-x-y / 2} \mathrm{Nb}_{y} \mathrm{Zr}_{1-y} \mathrm{O}_{3}$ (Chincholkar et al 1969). 
(A) Cubic perovskite exists in the Zr-rich portion. The lattice parameter $a$ increases linearly with $\mathrm{Ba}^{2+} / \mathrm{Nb}^{5+}$ ratio due to the differences in ionic radii. Density and $\mathrm{x}$-ray intensity data suggest that these compositions have varancies in the $\mathrm{A}$ sites, as in $\mathrm{Ba}(\mathrm{Ti}, \mathrm{Nb}) \mathrm{O}_{3}$ system (Subbarao and Shirane 1959).

(B) Cubic pyrochlore exists in the Pb-rich compositions and can be indexed on the basis of $\mathrm{A}_{2} \mathrm{~B}_{2} \mathrm{O}_{7}$ compounds. Density and $\mathrm{X}$-ray intensities suggest vacancies in the $\mathrm{A}$ and oxygen sites, as in $\mathrm{Pb}_{1.5} \mathrm{Nb}_{2} \mathrm{O}_{6.5}$ (Cook and Jaffe 1953).

(C) Tetragonal $\mathrm{PbTiO}_{3}$ type occurs in the narrow composition range of $\mathrm{Ba}^{2+}$ $(0 \cdot 55-0 \cdot 70)$ and $\mathrm{Nb}^{5+}(0.55-0 \cdot 70)$. A study of the dielectric properties of these compositions (Chincholkar et al 1970) shows that the Curie temperature $\left(T_{c}\right)$ decreases with increasing $c / a$ (figure 5). At fixed $\mathrm{Nb}^{5+}$ concentration, the $c / a$ values were reported to increase with increasing $\mathrm{Ba}^{2+}$ concentration, possibly due to the larger size of $\mathrm{Ba}^{2+}(1.43 \AA)$ than that of $\mathrm{Pb}^{2+}(1.32 \AA)$ and are larger than that for $\mathrm{PbTiO}_{3}$ for many compositions. Since the polarizability of $\mathrm{Ba}^{2+}\left(74.8 \mathrm{~A}^{3}\right)$ is lower than that of $\mathrm{Pb}^{2+}\left(89.5 \AA^{3}\right)$, it is expected that a decrease in $T_{c}$ should occur with increasing $\mathrm{Ba}^{2+}$ concentration (and increasing $c / a$ ). One observes a linear decrease in $T_{c}$ with decreasing average polarizability of $A$ site $(\mathrm{Ba}+\mathrm{Pb})$ ions at fixed $\mathrm{Nb}^{5+}$ concentration) (figure 5).

(D) Tetragonal tungsten bronze type, similar to tetragonal $\mathrm{PbNb}_{2} \mathrm{O}_{6}(a=b=12.46$ and $c=3.907 \mathrm{~A}$ ), occurs in the $\mathrm{Nb}^{5+}$ rich region. Density data suggest vacancies in the $B$ and oxygen sites.

(E) Orthorhombic tungsten bronze type occurs near the $\mathrm{PbNb}_{2} \mathrm{O}_{6}$ corner of the diagram. The orthorhombic distortion $b / a$ and $\mathrm{V}^{1 / 3}$ decrease with decreasing

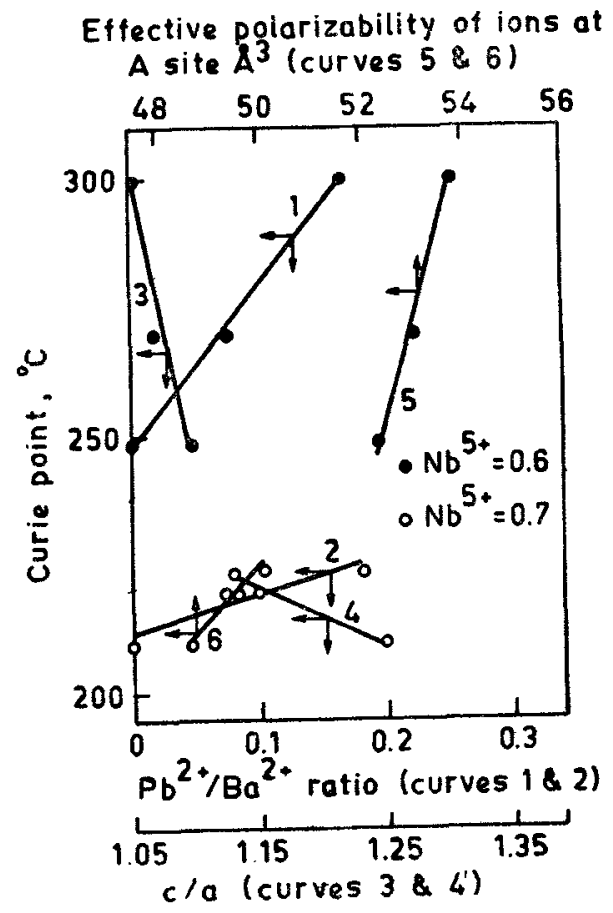

Figure 5. Variation of Curie temperature of tetragonal $\mathrm{PbTiO}_{3}$ type phase as a function of $c / a$ ratio, $\mathrm{Pb} / \mathrm{Ba}$ ratio and average polarizability of $\mathrm{A}$ site ions (Chincholkar et al 1970). 
$\mathrm{Pb}^{2+} / \mathrm{Ba}^{2+}$ ratio when $\mathrm{Nb}^{5+}$ content is kept constant at 0.90 , similar to that in the (Ba, $\mathrm{Pb}) \mathrm{Nb}_{2} \mathrm{O}_{6}$ solid solutions. At $\mathrm{Ba}^{2+}>0.2$, the lattice becomes that of tetragonal tungsten bronze type for $\mathrm{Nb}^{5+}=0.90$.

(F) Mixed phases are observed between the various structure types-perovskite (cubic and tetragonal), pyrochlore, and tungsten bronze (tetragonal and orthorhombic).

These studies enable one to engineer a desired crystal structure of a given type and symmetry and thereby achieve controlled dielectric properties.

\section{Defect structure}

\subsection{Introduction}

A multilayer capacitor is made by sintering a stack consisting of alternate layers of ceramic titanate dielectric and electrodes in a single operation. The electrode for this purpose should have a melting point above the sintering temperature $\left(1300-1400^{\circ} \mathrm{C}\right)$, be stable under the sintering conditions and not react with the dielectric. Palladium and $\mathrm{Pd}-\mathrm{Ag}$ alloys are among the few possible electrode materials. The escalating price of these materials prompts the use of the base metal electrodes (e.g. Ni), even though these electrodes require sintering in reducing atmospheres. Barium titanate under such conditions becomes highly conducting, due to the conversion of $\mathrm{Ti}^{4+}$ ions into $\mathrm{Ti}^{3+}$ ions accompanying the formation of oxygen vacancies, according to

$$
\mathrm{BaTi}^{4+} \mathrm{O}_{3} \stackrel{\text { reduction }}{\longrightarrow} \mathrm{BaTi}_{1-2 x}^{4+} \mathrm{Ti}_{2 x}^{3+} \mathrm{O}_{3-x}+{ }_{2}^{x} \mathrm{O}_{2} \text {. }
$$

Incorporation of some impurity ions [e.g. Mn (Herbert 1963, 1965; Burn 1978, 1979), Ga (Seuter 1974; Daniels 1978), Cr, Mg, Co (Burn and Maher 1975)] was found to prevent or minimize reduction of $\mathrm{BaTiO}_{3}$ under appropriate conditions. Of these, manganese has been reported to be most effective. Recent studies have clarified the role of $\mathrm{Mn}$.

\subsection{Energetics}

The free electrons which arise when $\mathrm{BaTiO}_{3}$ is reduced can be trapped at the positive ion (Ba, Ti or impurity ion at $\mathrm{Ba}$ or $\mathrm{Ti}$ sites) or negative ion (oxygen or impurity halogen) sites. The site preferred for electron trapping is one which causes maximum decrease of lattice energy $(\Delta W)$. Following Mott and Littleton (1938),

$$
\Delta W=\underset{M^{m+}}{\mathrm{BE}} \underset{\mathrm{M}^{\mathrm{n}+}}{-\mathrm{I}} \mathrm{M}^{\mathrm{n}+} \rightarrow \mathrm{M}^{\mathrm{m}+},
$$

where $B E$ is the binding energy of the particular ion concerned and $I$ is the ionization potential for the specific case. The potential energy of two ions in the $\mathrm{BaTiO}_{3}$ lattice has been calculated using only the Coulombic term and the $\Delta W$ values have been evaluated for various impurity ions, using the above potential energy and standard ionization potentials in equation (2) (table 1) (Desu and Subbarao 1980). 
Table 1. Energy change due to change of oxidation state of the dopant in $\mathrm{BaTiO}_{3}$ cubic lattice.

\begin{tabular}{cc}
\hline $\begin{array}{c}\text { Dopant and change of } \\
\text { oxidation state }\end{array}$ & $\begin{array}{c}\text { Energy } \\
\text { change } \\
\text { (eV) }\end{array}$ \\
\hline At the $\mathrm{Ti}$ site: & \\
$\mathrm{Li}^{1+} \longrightarrow \mathrm{Li}^{0}$ & +15.84 \\
$\mathrm{Mg}^{2+} \longrightarrow \mathrm{Mg}^{1+}$ & +7.41 \\
$\mathrm{In}^{3+} \longrightarrow \mathrm{In}^{1+}$ & -2.72 \\
$\mathrm{Sc}^{3+} \longrightarrow \mathrm{Sc}^{2+}$ & -3.02 \\
$\mathrm{Al}^{3+} \longrightarrow \mathrm{Al}^{1+}$ & -3.09 \\
$\mathrm{Ti}^{4+} \longrightarrow \mathrm{Ti}^{3+}$ & -3.26 \\
$\mathrm{Tl}^{3+} \longrightarrow \mathrm{Tl}^{1+}$ & -6.05 \\
$\mathrm{Ga}^{3+} \longrightarrow \mathrm{Ga}^{1+}$ & -7.10 \\
$\mathrm{~V}^{3+} \longrightarrow \mathrm{V}^{2+}$ & -7.58 \\
$\mathrm{Fe}^{3+} \longrightarrow \mathrm{Fe}^{2+}$ & -8.91 \\
$\mathrm{Cr}^{3+} \longrightarrow \mathrm{Cr}^{2+}$ & -9.22 \\
$\mathrm{Mn}^{4+} \longrightarrow \mathrm{Mn}^{3+}$ & -11.26 \\
$\mathrm{Co}^{3+} \longrightarrow \mathrm{Co}^{2+}$ & -11.76 \\
$\mathrm{Mn}^{3+} \longrightarrow \mathrm{Mn}^{2+}$ & -11.94 \\
$\mathrm{Cu}^{2+} \longrightarrow \mathrm{Cu}^{1+}$ & -14.39 \\
$\mathrm{Ni}^{3+} \longrightarrow \mathrm{Ni}^{2+}$ & -14.43 \\
$\mathrm{Zn}^{2+} \longrightarrow \mathrm{Zn}^{1+}$ & -17.26 \\
$\mathrm{Mn}^{4+} \longrightarrow \mathrm{Mn}^{2+}$ & -26.16
\end{tabular}

At the Ba site:

\begin{tabular}{rr}
$\mathrm{Cs}^{1+} \rightarrow \mathrm{Cs}^{0}$ & +14.80 \\
$\mathrm{Rb}^{1+} \longrightarrow \mathrm{Rb}^{0}$ & +14.51 \\
$\mathrm{~K}^{1+} \longrightarrow \mathrm{K}^{0}$ & +14.35 \\
$\mathrm{Ba}^{2+} \longrightarrow \mathrm{Ba}^{1}+$ & +8.73 \\
\hline
\end{tabular}

The conversion of $\mathrm{Ti}^{4+}$ into $\mathrm{Ti}^{3+}$ ions can be prevented either by compensating the nonstoichiometry with acceptors (e.g. BaTi $i_{-x}^{4+} \mathrm{M}_{x}^{2+} \mathrm{O}_{3-x}$ ) or by introducing dopants which will trap the free electrons more effectively than by $\mathrm{Ti}^{4+}$ and remain in the lattice (e.g. $\left.\mathrm{BaTi}_{1-x}^{4+} \mathrm{M}_{x}^{2+} \mathrm{O}_{3-x}+{ }_{2}^{x} \mathrm{O}_{2}\right)$. The various ions which may be incorporated in $\mathrm{BaTiO}_{3}$ are classified into three types depending upon the role they play and the $\Delta W$ values: (i) Those ions which cannot act as effective electron traps and for which $\Delta W$ is less than that for $\mathrm{Ti}^{4+} \rightarrow \mathrm{Ti}^{3+}\left(\right.$ e.g. $\mathrm{Li}^{+}, \mathrm{Mg}^{2+}$, etc.); (ii) Those ions which act as electron traps but not as acceptors (i.e. cannot compensate for oxygen vacancies) (e.g. $\mathrm{Mn}^{4+}$ ) and (3) Those which can act both as acceptors and effective traps e.g. $\mathrm{Mn}^{3+}, \mathrm{Co}^{3+}, \mathrm{Cr}^{3+}, \mathrm{Fe}^{3+}, \mathrm{V}^{3+}, \mathrm{Ga}^{3+}$ which are arranged in order of $\Delta W$ values and also of efficiency in preventing reduction of $\mathrm{BaTiO}_{3}$. This sequence is in general agreement with that found by Burn and Maher (1975).

\subsection{Defect structure of $\mathrm{Mn}$-doped $\mathrm{BaTiO}_{3}$}

The defect structure of pure and doped $\mathrm{BaTiO}_{3}$ has been studied as a function of oxygen partial pressure $\left(\mathrm{P}_{2}\right)$ and temperature (Daniels 1978; Chan and Smyth 1976; 
Smyth 1976, 1977; Daniels and Hardtl 1976; Wernicke 1976). Detailed investigation (Seuter 1974; Chan and Smyth 1976; Veitz and Veith 1965; Kosek and Arend 1967; Long and Blumenthal 1971; Eror and Smyth 1978) of the electrical conductivity of undoped $\mathrm{BaTiO}_{3}$ in the temperature range $600-1200^{\circ} \mathrm{C}$ revealed a $p$-type region near $\mathrm{Po}_{2} \simeq 1$ where the conductivity increases with increasing $\mathrm{P}_{2}$ and an $n$-type region at $\mathrm{PO}_{2} \approx 10^{-6}$ where the conductivity increases with decreasing $\mathrm{PO}_{2}$. The model proposed by Eror and Smyth (1978) can explain many of the observed facts and assumes the availability of free oxygen vacancies which are necessary to compensate a net excess of accidential negatively-charged impurities such as acceptor impurities which may be generalized as $A^{\prime}$.

In the case of acceptor doped $\mathrm{BaTiO}_{3}$, the charge neutrality condition becomes

$$
2\left[\mathrm{~V}_{\mathrm{o}}\right]=\left[A^{\prime}\right],
$$

where $\left[A^{\prime}\right]$ is the concentration of ionized acceptors out of a total of $\left[A_{\text {Tot }}\right]$ acceptors, leaving $[A]$ in a neutral state.

If all the acceptors are ionized i.e. $\left[A^{\prime}\right]=\left[A_{\text {Tot }}\right]$, the hole concentration $p$ is directly proportional to $\left[A_{\text {Tot }}\right]^{\frac{1}{2}}$ which implies

$$
\sigma \propto\left[A_{\mathrm{Tot}}\right]^{\frac{1}{2}} \text { or } \mathrm{P}\left[A_{\mathrm{Tot}}\right]^{\frac{1}{2}}=\text { constant. }
$$

If, on the other hand, none of the acceptors is ionized, the resistivity is independent of Mn concentration.

The decrease of electrical resistivity at a given temperature with $\mathrm{Mn}$ content (figure 6a) and the near constancy of $P\left[\mathrm{Mn}_{\mathrm{Tot}}\right]^{\frac{1}{2}}$ (table 2) confirm that $\mathrm{Mn}$ is fully ionized under these conditions (Desu and Subbarao 1981a). At a given temperature and $\mathrm{Mn}$ concentration, the resistivity increases with decreasing $\mathrm{Po}_{2}$ (figure $6 \mathrm{~b}$ ), indicating that the incorporation of $\mathrm{Mn}$ extends the $p$-type region of BaTiO $_{3}$ to lower $\mathrm{PO}_{2}$ and shifts the onset of the $p$-type behaviour to lower $\mathrm{PO}_{2}$ at a

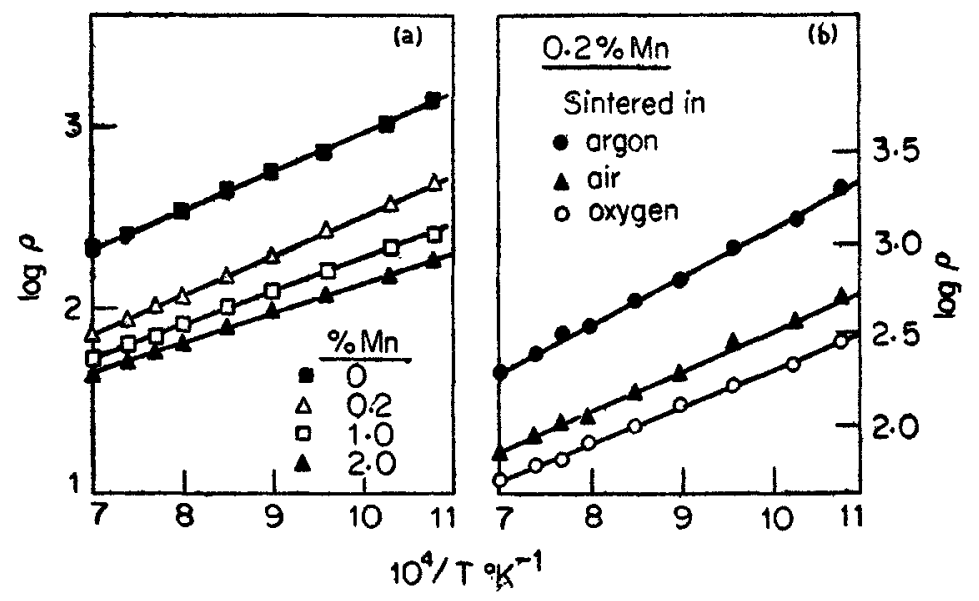

Figure 6. Variation of resistivity of $\mathrm{Mn}$-doped $\mathrm{BaTiO}_{3}$ (a) in air as a function of Mn content (b) for $0.2 \% \mathrm{Mn}$ as a function of sintering atmospheres (after Desu and Subbarao 1981a). 
given temperature or to higher temperatures at a given $\mathrm{P}_{2}$. When sintered pure $\mathrm{BaTiO}_{3}$ is heat-treated in $\mathrm{H}_{2}$ between 500 and $1100^{\circ} \mathrm{C}$ the resistivity decreases steeply, while incorporation of $\mathrm{Mn}$ (even $0.2 \%$, but preferably $1-2 \%$ ) enables $\mathrm{BaTiO}_{3}$ to resist reduction in $\mathrm{H}_{2}$ up to $900^{\circ} \mathrm{C}$ (figure 7). If a mixture of $75 \% \mathrm{~N}_{2}, 25 \% \mathrm{H}_{2}$ is used, the temperature of heat treatment can be extended to higher temperatures without a large reduction in resistivity (table 3 ).

\subsection{Oxidation state of $M n$}

DTA studies of $\mathrm{BaCO}_{3}+\mathrm{TiO}_{2}+\mathrm{Mn}_{2} \mathrm{O}_{3}$ or $\mathrm{MnO}_{2}$ show a peak at $1020^{\circ} \mathrm{C}$, corresponding to the $\mathrm{Mn}_{2} \mathrm{O}_{3} \rightarrow \mathrm{Mn}_{3} \mathrm{O}_{4}$ transformation (figure 8). The weight loss data are also consistent with this. Thus, $\mathrm{MnO}_{2}$ and $\mathrm{Mn}_{2} \mathrm{O}_{3}$ get converted to $\mathrm{Mn}_{3} \mathrm{O}_{4}$ before incorporation in $\mathrm{BaTiO}_{3}$.

The ESR spectra of $0.2 \% \mathrm{Mn}$ doped $\mathrm{BaTiO}_{3}$ (sintered at $1380^{\circ} \mathrm{C}$ for $2 \mathrm{hr}$ in air) show the presence of $\mathrm{Mn}^{4+}(g=1.994)$ and $\mathrm{Mn}^{2+}(g=2.0024)$ (figure 9). Semiquantitative estimates indicate presence of $\mathrm{Mn}^{3+}$ also, which cannot be detected by ESR, except at lower temperatures than employed here. It is inferred that $\mathrm{Mn}^{3+}$ is the major species and $\mathrm{Mn}^{2+}$ and $\mathrm{Mn}^{4+}$ are present in smaller concentrations. It may be noted in table 2 that the product $P\left[\mathrm{Mn}_{\text {Tot }}\right]^{\frac{1}{2}}$ deviates from constancy at high temperatures (1100 and $1428 \mathrm{~K}$ ). While $\mathrm{Mn}$ exists as $\mathrm{Mn}^{2+}, \mathrm{Mn}^{3+}$ and $\mathrm{Mn}^{4+}$ in BaTiO $_{3}, \mathrm{Mn}^{4+}$ on $\mathrm{Ti}^{4+}$ sites has no effect of $\mathrm{BaTiO}_{3}, \mathrm{Mn}^{2+}$ on $\mathrm{Ti}^{4+}$ sites may exist as $\mathbf{M n}^{\prime}{ }_{\mathbf{T}}$ or $\mathbf{M n}^{\prime \prime}{ }_{\mathbf{T}}$, the latter being improbable due to its high ionization energy. Then,

Table 2. Variation of resistivity of $\mathrm{BaTiO}_{3}$ with $\mathrm{Mn}$ content.

\begin{tabular}{|c|c|c|c|c|c|c|c|}
\hline \multirow{2}{*}{$\begin{array}{l}\text { Mn } \\
\%\end{array}$} & \multirow{2}{*}{$\mathbf{A}_{\text {Tot }}$} & \multicolumn{3}{|c|}{$\rho, 10^{2}$} & \multicolumn{3}{|c|}{$\rho\left[\mathrm{A}_{\text {Tot }}\right]^{\frac{1}{2}}, 10^{11}$} \\
\hline & & 909 & 1110 & $1428 K$ & 909 & 1110 & $1428 \mathrm{~K}$ \\
\hline 0.2 & $3.2 \times 10^{! 8}$ & 5.6 & 2.0 & 0.71 & 31.7 & 11.3 & 4.0 \\
\hline 1.0 & $1.6 \times 10^{20}$ & 2.8 & 1.3 & 0.54 & 35.3 & 16.4 & 6.8 \\
\hline 2.0 & $3.2 \times 10^{20}$ & 2.0 & 1.0 & 0.45 & 35.8 & 17.9 & 8.1 \\
\hline
\end{tabular}

Table 3. Room temperature resistivity of specimens heated in $\mathrm{H}_{2}$ and in $75 \% \mathrm{~N}_{2}$ $25 \% \mathrm{H}_{2}$ at $1100^{\circ} \mathrm{C}$ for $10 \mathrm{~min}$.

\begin{tabular}{ccccc}
\hline $\begin{array}{c}\mathrm{Mn} \\
\%\end{array}$ & $\begin{array}{c}\mathrm{Ba} / \mathrm{Ti} \\
\mathrm{H}_{2}\end{array}$ & $\begin{array}{c}1.0 / 0.98 \\
75 \mathrm{~N}_{2} 25 \mathrm{H}_{2}\end{array}$ & $\begin{array}{c}\mathrm{Ba} / \mathrm{Ti} \\
\mathrm{H}_{2}\end{array}$ & $\begin{array}{c}1.0 / 1.02 \\
75 \mathrm{~N}_{2} 25 \mathrm{H}_{2}\end{array}$ \\
\hline 0 & $7.94 \times 10^{2}$ & $3.98 \times 10^{5}$ & $1.99 \times 10^{2}$ & $1.5 \times 10^{6}$ \\
0.2 & $1.99 \times 10^{5}$ & - & $1.0 \times 10^{4}$ & $3.99 \times 10^{6}$ \\
1.0 & $3.16 \times 10^{5}$ & $1.0 \times 10^{7}$ & $5.1 \times 10^{4}$ & $6.30 \times 10^{5}$ \\
2.0 & $6.31 \times 10^{5}$ & $1.27 \times 10^{7}$ & $1.26 \times 10^{5}$ & $1.58 \times 10^{7}$ \\
\hline
\end{tabular}




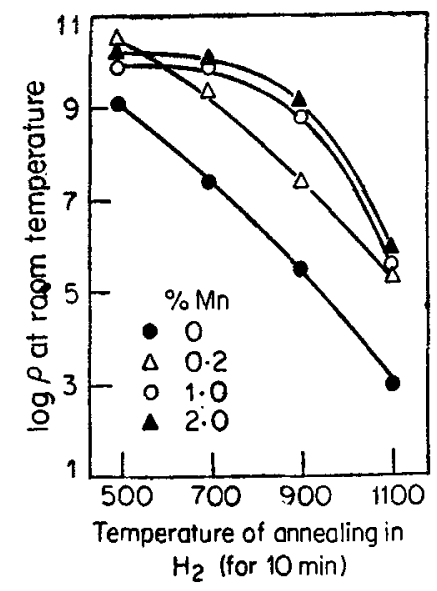

Figure 7. Room temperature electrical resistivity of $\mathrm{Mn}$-doped $\mathrm{BaTiO}_{3}$ as a function of temperature of annealing in $\mathrm{H}_{2}$ (for $10 \mathrm{~min}$ ) (after Desu and Subbarao 1981a).

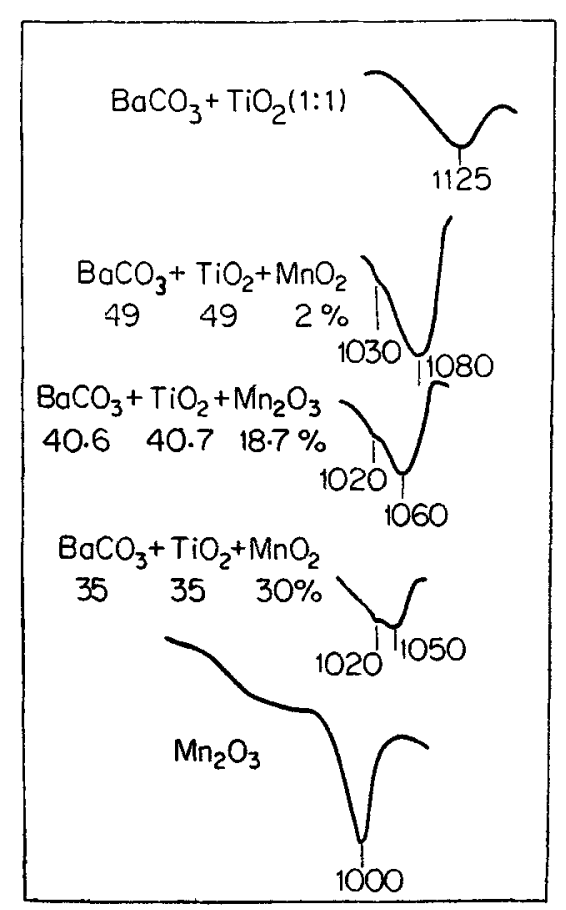

Figare 8. A part of DTA traces of mixtures of $\mathrm{BaCO}_{3}, \mathrm{TiO}_{2}$ and $\mathrm{Mn}_{2} \mathrm{O}_{3}$ or $\mathrm{MnO}_{2}$ (Desu and Subbarao 1981a).

$\mathrm{Mn}^{2+}$ on $\mathrm{Ti}^{4+}$ is effectively equivalent to $\mathrm{Mn}^{3+}$. Increase of $\left[\mathrm{Mn}^{4+}\right]$ with dopant concentration (as shown by ESR data) increases the electrical resistivity so that the product $P\left[\mathrm{Mn}_{\mathrm{Tot}}\right]^{\frac{1}{2}}$ increases with $[\mathrm{Mn}]$ content at a given temperature, instead of remaining constant. Heating $\mathrm{Mn}$-doped $\mathrm{BaTiO}_{3}$ in hydrogen increases the $\left[\mathrm{Mn}^{2+}\right]$ 

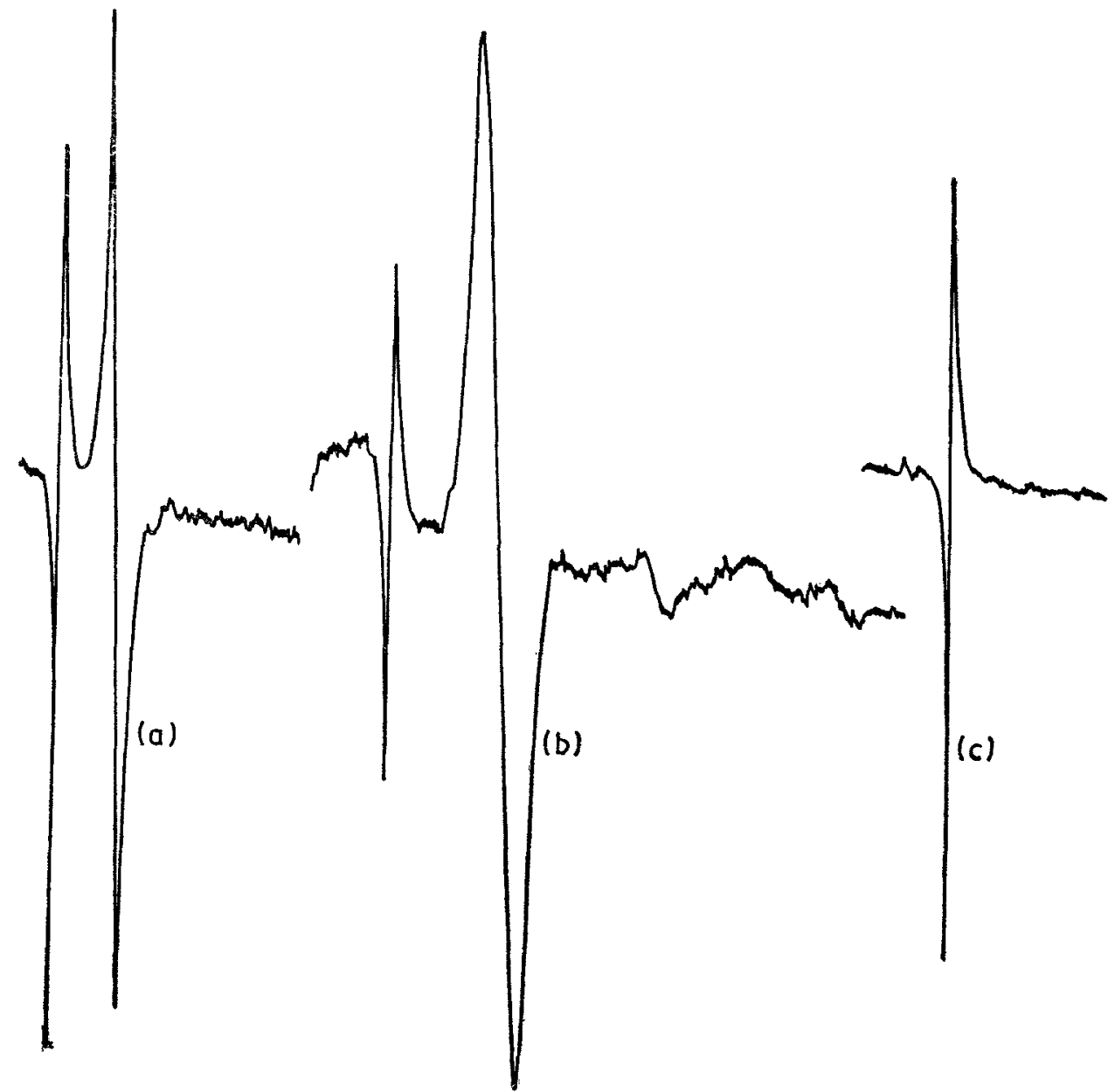

Figure 9. Room temperature EPR spectra of barium titanyl oxalate doped with $\mathbf{0 . 2}$ percent $\mathrm{Mn}$, sintered at $1380^{\circ} \mathrm{C}$ for $2 \mathrm{hr}$ in (a) air, (b) argon and (c) hydrogen (Desu and Subbarao 1981a).

as the temperature of heat treatment is varied from 500 to $1200^{\circ} \mathrm{C}$ (figure 10). At higher temperatures $\left(1380^{\circ} \mathrm{C}\right.$ in hydrogen $), \mathrm{MnO}$ was found to be exsolved.

\subsection{Phase stability of $\mathrm{Mn}$-doped $\mathrm{BaTiO}_{3}$}

The Curie (cubic-tetragonal transition) temperature of $\mathrm{BaTiO}_{3}$ is hardly affected by $\mathrm{Mn}$-doping, while it is greatly lowered by other transition metal ions e.g. Fe, $\mathrm{Ni}$ and $\mathrm{Zn}$ ions. The stabilization of the tetragonal structure can be explained by the Jahn-Teller effect on $\mathrm{Mn}^{3+}$, since $\mathrm{Mn}^{2+}$ and $\mathrm{Mn}^{4+}$ are inactive in this. respect. On the basis of the Jahn-Teller distortions, $\mathrm{Mn}^{3+}$ has been shown (Desu and Subbarao 1981b) to favour tetragonal distortion $(c / a>1)$, whereas $\mathrm{Mn}^{2+}$ and $\mathrm{Mn}^{4+}$ stabilize the cubic and rhombohedral phases relative to others. This concept also explains the greater stability of the tetragonal and orthorhombic phases at high $\mathrm{PO}_{2}$ and tendency for the formation of the cubic phase at low $\mathrm{PO}_{2}$, where the $\mathrm{Mn}^{2+}$ content is more. 


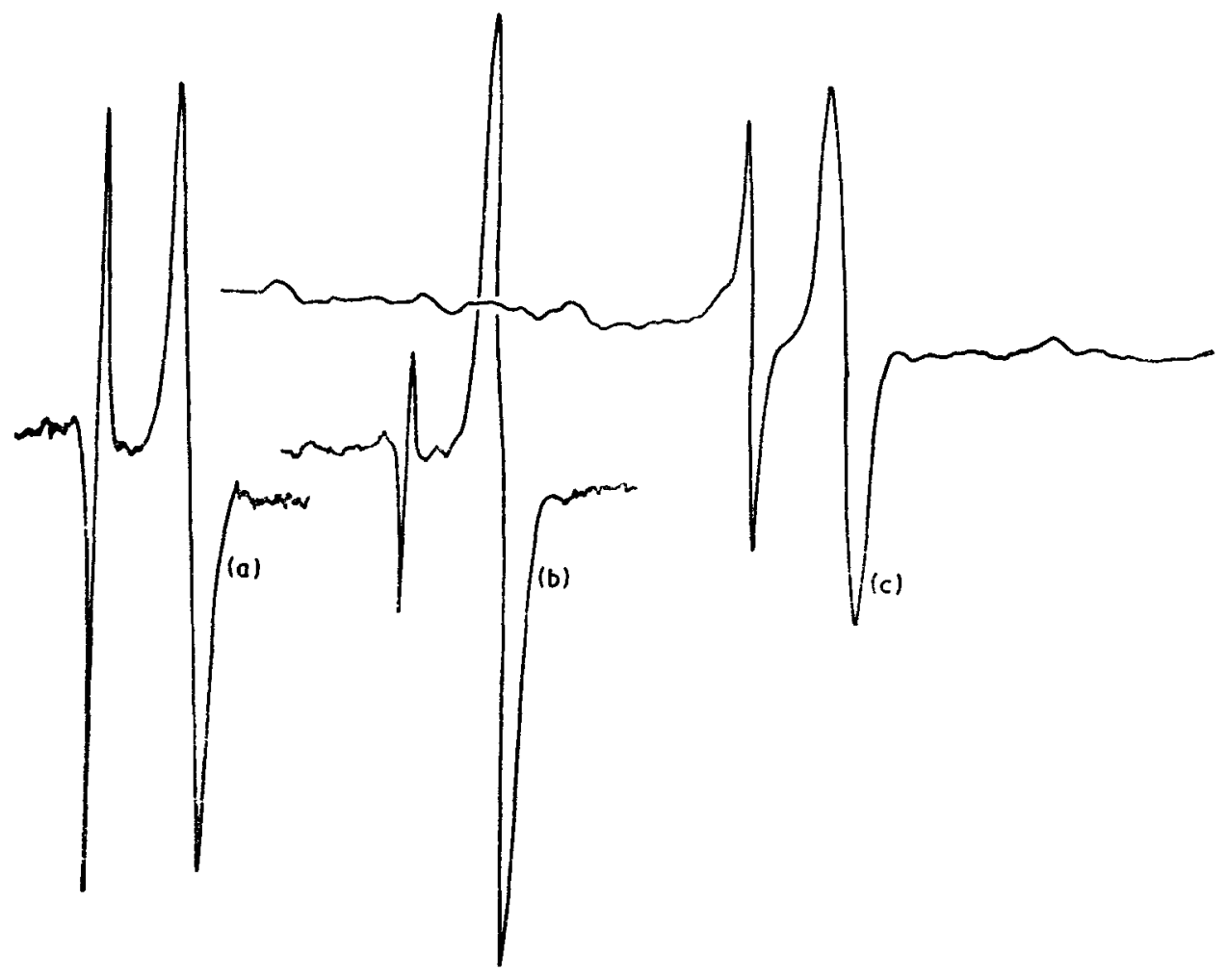

Figure 10. Room temperature EPR spectra of barium titanyl oxalate, doped with $0.2 \% \mathrm{Mn}$, sintered at $1380^{\circ} \mathrm{C}$ for $2 \mathrm{hr}$ in air, followed by annealing in hydrogen for 10 min. at (a) $500^{\circ} \mathrm{C}$, (b) $900^{\circ} \mathrm{C}$ and (c) $1200^{\circ} \mathrm{C}$ (Desu and Subbarao 1981a).

\section{Composites}

\subsection{Introduction}

When a new material with important properties is discovered (e.g. $\mathrm{BaTiO}_{3}$ as a high dielectric constant material in early 1940's or lead zirconate titanate [PZT] as an excellent piezoelectric material in early 1950 's), intense materials science activity for molecular designing of other materials based on them starts. But quite often these efforts lead to some, but not order of magnitude, improvement in behaviour. Then one resorts to composites of two or more materials, each with some of the desired properties. The objective of such a study is (i) to select materials which have some of the desired characteristics, (ii) to combine them in such a way that the 'sum' properties are optimised and (iii) to explore the possibility of unexpected 'product' properties. Next in importance to the properties of the individual materials is the processing technology to establish the desired connectivity of the phases. Designing of composites based on these concepts was first suggested by van Suchtelen (1972) and elaborated by Newnham et al $(1978,1980)$ and Skinner et al (1978) for dielectric, piezoelectric and pyroelectric materials. 


\subsection{Connectivity}

Referred to three orthogonal axes, each phase in a composite may be self-connected in zero, one, two or three dimensions. The ten different connectivities possible in a diphasic material are illustrated in figure 11, where arrows are used to indicate the connected directions and two views of the 3-3 and 3-2 patterns are shown for clarity. The 2-1 connectivity pattern has one phase self-connected in two dimensional layers, the other self-connected in one-dimensional chains or fibers, both of which may be parallel or perpendicular to each other. Extrusion of a ceramic slip through a die can give a three-dimensionally connected block containing one-dimensional holes, giving a 3-1 connectivity. Tape casting of alternate layers of a dielcctric and a metal electrode, as in multilayer capacitors, represent 2-2 connectivity. The 3-3 connectivity pattern in which the two phases form interpenetrating threc-dimensional networks exists in living systems such as coral where orgaric tissuc and inorganic skeleton interpenetrate one another. Other examples of 3-3 conncctivity are some polymer foams, phase-separated glasses, wood, etc.

Some examples of connectivity to enhance properties of oxide dielectrics are:

Liquid-phase-sintered capacitor materials in which ba:ium titanate grains are coated by a three-dimensionally connected liquid phase of $\mathrm{NaNbO}_{3}$ represent a 3-0
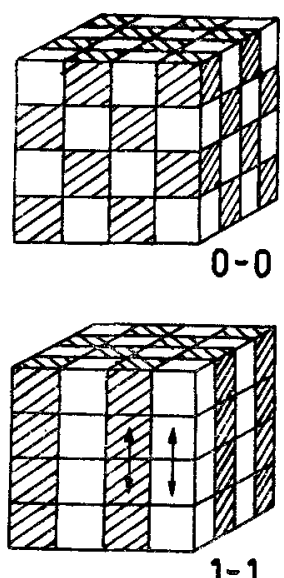

1-1

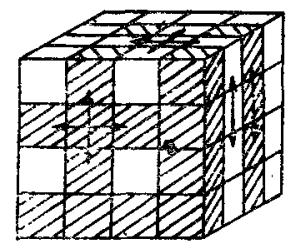

$\stackrel{1}{Z} Y^{3-2}$
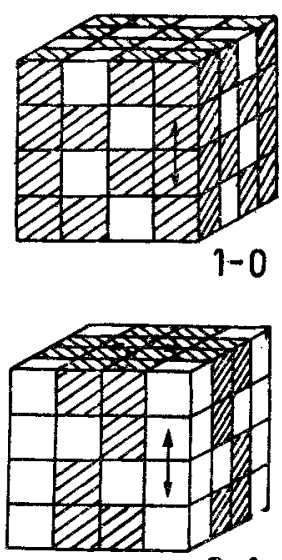

2-1
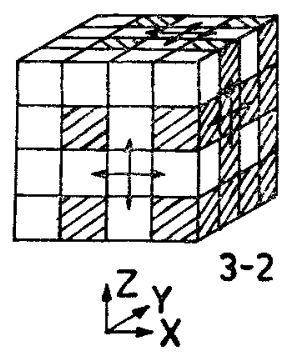
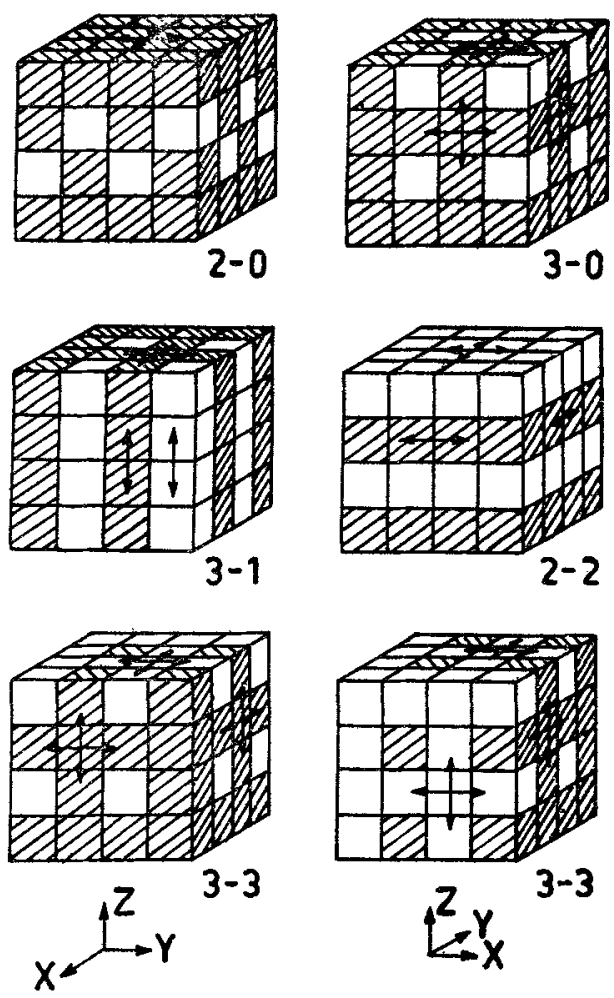

Figure 11. Ten connectivity patterns for a diphasic solid. Each phase has zero-, one-, two or three-dimensional connectivity to itself. Arrows indicate the connected directions. The 3-3 and 3-2 patterns are shown in two views for clarity (after Newnham et al 1978). 
connectivity. Barium titanate suffers diclectric saturation, whereby the dielectric constant drops to hali its origina! value when a sufficient electric field is applied. This is prevented by the thin cuating of antiferroelectric $\mathrm{NaNbO}_{3}$ around $\mathrm{BaTiO}_{3}$ grains in the diphasic material rosulting in a flat voltage response (Payne 1973). A macrostructure with 3-1 connectivity is achieved in an extruded $\mathrm{BaTiO}_{3}$ honeycomb with empty channels which are used for electroding. The sizable electric fields which can be applied across the thin ceramic walls are utilized in electrostrictive micropositioner for adaptive optic systems. The 2-2 connectivity exists in a multilayer composite of 'soft' and 'hard' PZT, where the hard PZT keeps the soft PZT, with its high piezoelectric response, in a poled state. The properties of the composite are superior to those of a single phase material. The 3-3 connectivity is achieved by a replamine process. It consists of (i) machining coral to the desired geometry, (ii) vacuum-impregnating with wax, followed by hardening of wax, (iii) leaching calcium carbonate skeleton in hydrochloric acid, (iv) vacuum-impregnating the wax negative with a PZT slurry (PZT $43 \%$ by volume, $\mathrm{H}_{2} \mathrm{O} 53 \%$, PVA 4 pct.), (v) burning off wax at $300^{\circ} \mathrm{C}$, (vi) sintering coral-like PZT at $1280^{\circ} \mathrm{C}$ for $1 \mathrm{hr}$. (vii) back-filling with a suitable polymer (Dow Corning MDX-4-4210 Elastomer), (viii) applying silver loaded silicon rubber electrodes to the cleaned surface and (ix) poling at a field strength of $14 \mathrm{kV} / \mathrm{cm}$ for $5 \mathrm{~min}$ at $100^{\circ} \mathrm{C}$. Starting with this rigid composite, a flexible composite may be obtained by crushing the ceramic to break the ceramic connectivity but the polymer matrix still holding the poled piezoelectric pieces in place. The properties of homogeneous PZT and rigid and flexible composites are compared in table 4 . The remarkable decrease in permittivity $\left(\varepsilon_{R}\right)$ and increase in longitudinal piezoelectric voltage coefficient $\left(g_{33}=d_{33} / \varepsilon_{33}\right)$ of the composites may be noted compared to those of homogeneous PZT. These composites are useful to fabricate low density, high coupling resonators and hydrophones.

An example of composites with 3-1 connectivity consists of embedding aligned PZT rods in a plastic matrix. When the two phases are connected in parallel, the properties of the composite are given by

$$
\begin{aligned}
\bar{d}_{33} & =\frac{{ }^{1} v^{1} d_{33}{ }^{2} s_{33}+{ }^{2} v^{2} d_{33}{ }^{1} s_{33}}{{ }^{1} v^{2} s_{33}+{ }^{2} v^{1} s_{33}}, \\
\bar{g}_{33} & =\frac{{ }^{1} v^{1} d_{33}{ }^{2} s_{33}+{ }^{2} v^{2} d_{33}{ }^{1} s_{33}}{\left({ }^{1} v^{2} s_{33}+{ }^{2} v^{1} d_{33}\right)\left({ }^{1} v^{1} \varepsilon_{33}+{ }^{2} v^{2} \varepsilon_{33}\right.},
\end{aligned}
$$

where the superscripts 1,2 refer to the two phases, $v, d, s, \varepsilon$ refer to the volume fraction, piezoelectric coefficient, elastic compliance and dielectric permittivity, respectively. For a composite of a mechanically stiff ferroelectric (phase 1) in parallel in a soft, compliant polymer (phase 2 ), ${ }^{1} d \gg^{2} d,{ }^{1} s{ }^{2} s,{ }^{1} \varepsilon \gg^{2} \varepsilon$ and therefore $\bar{d}_{33} \approx{ }^{1} d_{33}$, $\bar{g} \approx{ }^{1} d_{33} /{ }^{2} v^{1} \varepsilon_{33}$. Volume fraction, diameter and spacing of the rods are parameters which can be easily varied. PZT rods are extruded from a suitable slip, dried and then sintered at $1305^{\circ} \mathrm{C}$ for $30 \mathrm{~min}$ initially and finally in a hot isostatic press at $1300^{\circ} \mathrm{C}$ for $1 \mathrm{hr}$ at 200 atmospheres of argon. The dense rods $\left(7.82 \mathrm{~g} / \mathrm{cm}^{3}\right)$ are located in perforated brass plates for alignment and the empty spaces filled with an epoxy. After setting, the assembly is cut into plates and poled in an oil bath at $75^{\circ} \mathrm{C}$ at $22 \mathrm{kV} / \mathrm{cm}$ for $5 \mathrm{~min}$. As expected, $\bar{d}_{33}$ is independent of the volume fraction of PZT between 20 and $50 \%$ (figure 12). For this geometry, 
Table 4. Properties of homogeneous PZT and composites.

\begin{tabular}{lccc}
\hline Property & $\begin{array}{c}\text { Homogeneous } \\
\text { PZT }\end{array}$ & \multicolumn{2}{c}{$3-3$ Composite } \\
\cline { 3 - 4 } Density $\times 10^{3} \mathrm{~kg} / \mathrm{m}^{3}$ & 7.9 & 3.3 & 3.3 \\
Compliance & Low & Low & High \\
$d_{33} \times 10^{-12} \mathrm{C} / \mathrm{N}$ & 400 & 160 & 100 \\
$\epsilon$ & 2000 & 100 & 40 \\
${ }_{R}$ & 20 & 160 & 300 \\
\hline$g_{33} \times 10^{-3} \mathrm{VM} / \mathrm{N}$ & & & \\
\hline
\end{tabular}

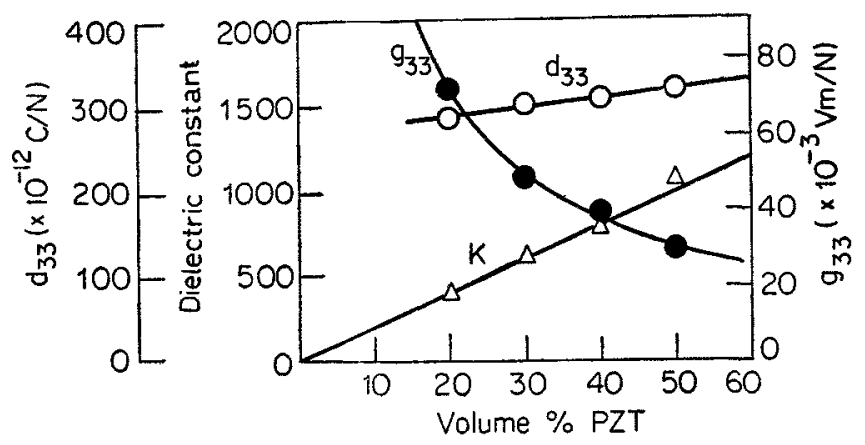

Figure 12. Variation of $\mathrm{K}, d_{33}$ and $g_{33}$ as a function of volume per cent PZT (after Newnham et al 1980).

$\bar{\varepsilon}={ }^{1} v /{ }^{1} \varepsilon_{33}+{ }^{2} v^{2} \varepsilon_{33}$. Since ${ }^{1} \varepsilon_{33}(2000) \gg{ }^{2} \varepsilon_{33}(\sim 4), \varepsilon_{x}{ }^{1} v^{1} \varepsilon_{33}$, which agrees with the experiment (figure 12). The $\bar{g}_{33}$ value increases steeply at low volume fraction of $\mathrm{PZT}$, due to the small values of $\varepsilon$ for these composites. At $20 \% \mathrm{PZT}, \bar{g}_{33}$ is about 3.5 times that of solid PZT (figure 12). Helical spirals of PZT are made by winding green rods on a mandrel. After drying and firing they are embedded in a plastic in a bed spring array. These also lead to interesting effects.

\section{Conclusions}

Based on the physics and chemistry of the solid state, to which Professor A B Biswas has made notable contributions, engineering of crystal structure, defect structure, microstructure and macrostructure is shown to lead to oxide dielectric materials of technological interest with properties sometimes improved by orders of magnitude.

\section{Acknowledgement}

The author is grateful to S B Desu, whose work is utilized here, and to the Department of Electronics, Government of India, for financial support. 


\section{References}

Burn 11978 Am. Ceram. Soc. Bull. 57600

Burn I 1979 J. Mater. Sci. 142453

Burn I and Maher G H 1975 J. Mater. Sci. 10633

Chan N W and Smyth D M 1976 J. Electrochem. Soc. 1231584

Chincholkar V S, Sanjana N R and Biswas A B 1969 Indian J. Pure Appl. Phys. 7724

Chincholkar V S, Biswas A B and Menezes C A 1970 Indian J. Pure Appl. Phys. 8707

Cook W R and Jaffe H 1953 Phys. Rev. 891297

Daniels J 1978 Philips Res. Rep. 31505

Daniels J and Hardtl K H 1976 Philips Res. Rep. 31489

Desu S B and Subbarao E C 1980 J. Mater. Sci. 152113

Desu S B and Subbarao E C 1981a Adv. Ceram. 1189

Desu S B and Subbarao E C 1981b Ferroelectries (in Press)

Eror N G and Smyth D M 1978 J. Solid State Chem. 24235

Francombe M H 1960 Acta Crystallogr. 13131

Francombe M H and Lewis B 1958 Acta Crystallogr. 11696

Herbert J M 1963 Trans. Bri. Ceram. Soc. 62648

Herbert J M 1965 Proc. I E E 1121474

Jona $F$ and Shirane G 1962 Ferroelectric crystals (New York: Pergamon Press)

Kosek F and Arend H 1967 Phys. Stat. Solidi. 24 K 69

Long S A and Blumenthal R N 1971 J. Am. Ceram. Soc. 54515577

Mott N F and Littleton J T 1938 Trans. Faraday Soc. 34485

Newnham R E, Skinner D P and Cross L E 1978 Mater. Res. Bull. 13525

Newnham R E, Skinner D P, Klicker K A, Bhalla A S, Hardiman B and Gururaja T R 1980 Ferroelectrics 2749

Payne D A $1973 \mathrm{Ph} . \mathrm{D}$. Thesis Pennsylvania State University

Seuter A M J H 1974 Philips Res. Rep. Suppl. No 31

Skinner D P, Newnham R E and Cross L E 1978 Mater. Res. Bull. 13599

Smyth D M 1976 J. Solid State Chem. 1673

Smyth D M 1977 J. Solid State Chem. 20359

Srikanta S, Tare V B, Sinha A P B and Biswas A B 1962 Acta Crystallogr. 15255

Subbarao E C and Shirane G 1959 J. Am. Ceram. Soc. 42279

Van Suchtelen J 1972 Philips Res. Rep. 2728

Veitz H and Veith H 1965 Z. Angew. Phys. 2016

Wernicke R 1976 Philips Res. Rep. 31526 